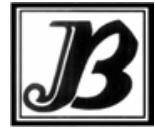

J. bio-sci. 14: 39-41, 2006

ISSN 1023-8654

\title{
A NEW SPECIES OF PREDATORY MITE, AMBLYSEIUS (ACARINA: PHYTOSEIIDAE) FROM STORED COFFEE BERRIES
}

\author{
Mary Anithalatha Sadanandan \\ $P G$ and Research Department of Zoology, \\ Malabar Christian College, Calicut, Kerala 04952760268
}

\begin{abstract}
A new species of predatory mite of the family Phytoseiidae viz., Amblyseius (Amblyseius) coffeae sp. nov. is described from stored coffee berries.
\end{abstract}

Key words: Predatory mite, Phytoseiidae, Amblyseius, new species.

\section{Introduction}

Predatory mites constitute a highly significant beneficial group on account of their vital role in the maintenance of pest population below the economic injury level. The species of Phytoseiidae are potentially important as a biotic factor in the control of phytophagous mites (Ewing 1914). Mass multiplication methods have been developed to use these predators in commercial scale on a variety of crops (Lo et al. 1979, Krishnamoorty 1982). Phytoseiidae contain 168 species under 12 genera (Gupta and Arun Gupta 1999). However, the reports on occurrence of new species are scanty from peninsular India. Hence a systematic survey was undertaken to unravel the occurrence of new species of Phytoseiidae from various districts of Kerala. The present new species was collected during this survey. The occurrence of phytoseiids in stored products is a very rare phenomenon, though isolated examples exists for the occurrence of members of Amblyseius and Neoseiulus in stored grains (Hughes 1976, Smiley 1984).

\section{Materials and Methods}

The predatory mite fauna harbouring on various stored commodities were collected by making extensive surveys in Kerala. Random samples of $100 \mathrm{gms}$ were collected in separate polythene bags and brought to the laboratory. They were then extracted in modified Berlese funnels constructed locally for 24 hours under 40 watts electric bulbs. The mites thus got extracted out of the samples were collected in $70 \%$ ethyl alcohol. They were then upgraded in alcohol series and then mounted in Hoyer's medium permanently. All the measurements are given in microns. All the type specimens have been deposited in the Division of Acarology, Department of Zoology, University of Calicut, Kerala.

\section{Results and Discussion}

Amblyseius (Amblyseius) coffeae sp. nov. (Figure 1).

Female: Dorsal shield smooth, 440 long and 307 wide with 17 pairs of setae, $j_{1}, j_{3}, s_{4}, Z_{4}$ and $Z_{5}$ long and the latter two being whip like, $Z_{5}$ the longest among the dorsal setae. $s_{4}>Z_{4}, j_{3}>j_{1}$. Measurements of the setae: $j_{1}-37, j_{3}-47, S_{4}-109, Z_{4}-99$ and $Z_{5}-244, Z_{2}, Z_{4}-8$ each, $Z_{1}, S_{2}, S_{5}-7$ each. $r_{3}, R_{1}-8$ each, both on the lateral integument, all other setae minute. Sternal shield longer (90) than broad (75) with 3 pairs of setae (30); metasternal plates with setae distinct. Genital shield 86 wide with a pair of setae (28). 

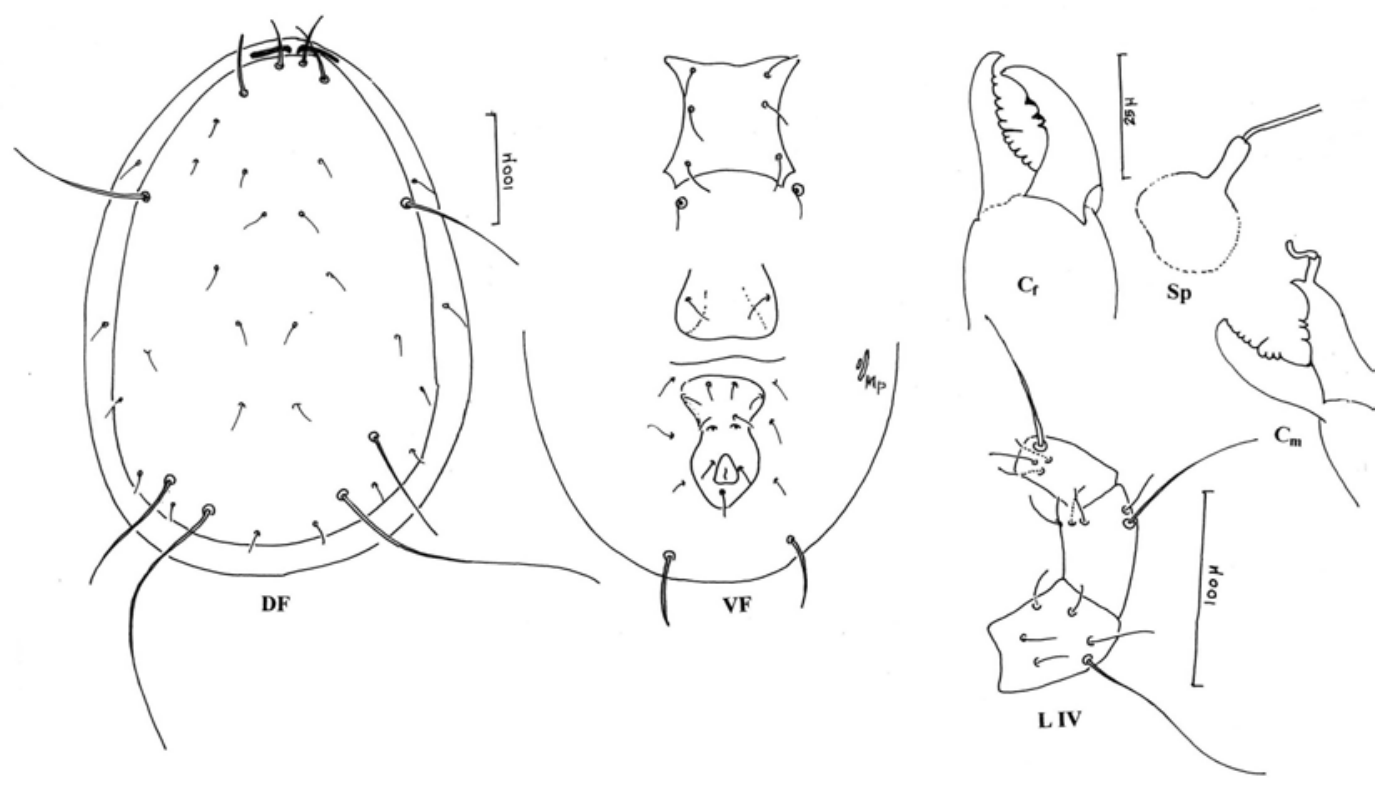

Fig. 1. Amblyseius (Amblyseius) coffeae sp. nov.

Ventrianal shield longer (109) than wide (49), vase-shaped, lateral margins concave with 3 pairs of preanal setae (22) and a pair of semilunar pores, little posterior to 3rd pair of preanal setae; 4 pairs of setae present on the membrane around ventrianal shield. Setae $\mathrm{JV}_{5}-62$ long, smooth; 2 pairs of metapodal plates present, primary one 26 long, accessory one 8 long. Fixed digit of chelicera multidentate with pilus dentilis, movable digit with 3 sharp teeth. Spermatheca with short tubular cervix. Peritreme extends anteriorly beyond $\mathrm{j} 1$ and curves down a little. Macrosetae on leg IV: genu - 105, tibia - 78, basitarsus - 68.

\begin{tabular}{|c|c|c|}
\hline & 22 & 12 \\
\hline Leg Chaetotaxy: genu II & $\begin{array}{cc}2 \text {---- } & 1, \\
0 & 0\end{array}$ & tibia II $\begin{array}{ccc}1 & --- & 1 ; \\
& 1 & 1\end{array}$ \\
\hline
\end{tabular}

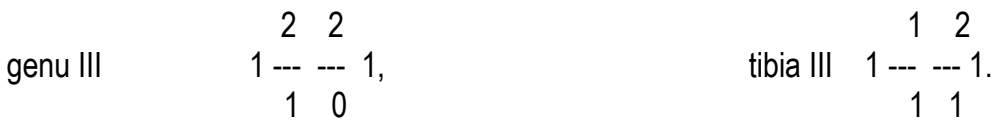

Male: Dorsal chaetotaxy similar to that of female. Spermatophoral process as illustrated. Macrosetae on Leg IV: genu - 90, tibia - 65, basitarsus - 60.

Habitat: Coffea arabica (Stored)

Material examined: Holotype $q$ marked on the slide along with other $39+9$ INDIA: KERALA: Mananthavady (Wayanad district), 8.ix.2000, ex. Coffea arabica (stored), coll: Mary Anitha (No. AS 24/1). One paratype slide with 4 우 and a $\hat{\partial}$, collection details same as that of holotype (No. AS 24/2). 
Remarks: This new species resembles $A$. (A.) largoensis Gupta (1986), in the shape of ventrianal shield and shape of spermatophoral process of male, but differs from it by the following characters:

1. The more elongated nature of the dorsal shield.

2. The length of $s_{4}(109)$ in the new species exeeds that of $Z_{4}(99)$ while in

A. (A.) largoensis (Gupta) $\mathrm{Z}_{4}$ is longer than $\mathrm{s}_{4}$.

3. Number of teeth on the movable digit of chelicera is 3 in the new species instead of 2 in $A$. (A.) largoensis (Gupta).

4. Cervix of the spermatheca is short in the new species while it is long in A. (A.) largoensis (Gupta).

Abbreviations: Cf - Chelicera of female, $\mathrm{Cm}$ - Chelicera of male, DF - Dorsal view of female, DM - Dorsal view of male, LIV-Leg IV. showing setation, Mp - Metapodal plate, Sp - spermatheca, VF - Ventral view of female, VM - Ventral view of male.

\section{Acknowledgements}

The author is thankful to the UGC, New Delhi for the financial support extended under the FIP. The author is indebted to Dr N Ramani, Reader, Department of Zoology, University of Calicut, India for guidance and constant inspiration.

\section{References}

Ewing H E (1914) The common red spider or spider mite. Bull. Ore. Agric. Exp. Stn. 121: 95

Gupta S K (1986) Fauna of India (Acari: Mesostigmata) Family Phytoseiidae. Zoological Survey of India, Calcutta. 350.pp.

Gupta S K and Arun Gupta (1999) Progress of taxonomic research on Indian mites upto the end of twentieth century and prospects of research in the next millennium. J. Acarol. 15 (1-2): 8-83.

Hughes A M (1976) The mites of stored food and houses. Tech. Bull. 9 Ministry of Agriculture, Fisheries and food, His Majesty's stationary office, London. 400.pp.

Krishnamoorthy A (1982) Mass rearing technique for a indigenous predatory mite Amblyseius tetranychivorous Gupta (Acarina: Phytoseiidae) in the laboratory. Entomon 7: 47-49.

Lo K C, Ho C C and Chen S T (1979) Artificial propagation of Amblyseius taiwanicus and its tolerance to some pesticides. J. Agri. Res. China 28: 251-259.

Smiley R L (1984) The ordinal and subordinal names of mites with a list of the mite pests of stored products, pp. 36-43. In: Proc. Third internat. Working conf. Stored Prod. Entomol. Kansas State University, Kansas, U S A. 